\title{
An improved criterion to minimize FE mesh-dependency in concrete structures subjected to blast and impact loading
}

\author{
H. G. Kwak \& H. G. Gang \\ Department of Civil and Environmental Engineering, KAIST, Korea
}

\begin{abstract}
In the context of an increasing need for reliability and safety in concrete structures under blast and impact loading conditions, the behavior of concrete under high strain rate condition has been an important issue. Since concrete subjected to impact loading associated with high strain rate shows quite different material behavior from that in the static state, several material models are proposed and used to describe the high strain rate behavior under blast and impact loading. In the process of modelling, in advance, mesh dependency in the used finite element (FE) is the key problem because simulation results under high strain-rate condition are quite sensitive to applied FE mesh size. It means that the accuracy of simulation results may be deeply dependent on FE mesh size in simulations. This paper introduces an improved criterion which can minimize the mesh-dependency of simulation results on the basis of the fracture energy concept, and HJC (Holmquist Johnson Cook), CSC (Continuous Surface Cap) and $\mathrm{K} \& \mathrm{C}$ (Karagozian \& Case) models are examined to trace their relative sensitivity to the used FE mesh size. To coincide with the purpose of the penetration test with a concrete plate under a projectile (bullet), the residual velocities of projectile after penetration are compared. The correlation studies between analytical results and the parametric studies associated with them show that the variation of residual velocity with the used FE mesh size is quite reduced by applying a unique failure strain value determined according to the proposed criterion.
\end{abstract}

Keywords: high strain rate concrete, penetration simulation, failure strain, mesh-dependency, fracture energy. 


\section{Introduction}

Under hard impact, blast and impulsive load condition, concrete shows quite different behavior compared to that in static state. Many material properties of concrete such as strength, tangent modulus and critical strain are changed with strain rate. There are two main reasons for this unique behavior. First reason is inertia resistance effect. Concrete is a brittle material which fails due to internal microcrack creation and propagation. Decrease in the amount of microcrack at certain stress level reduces the stiffness of material. Under high strain-rate condition, there is not enough time to generate and propagate microcracks. This lack of microcracking decreases the amount of deformation along the loading direction. This means that stiffness of material in loading direction increases. Therefore, higher stress level than static condition is needed to propagate enough microcracks for failure in enhanced stiffness direction. Second reason is lateral inertia confinement effect. Lateral expansion caused by Poisson's ratio effect is limited during impact loading due to lack of time to expand. This limitation shows similar effects like lateral confining stress which increase strength of the material. In these reasons, strength and critical strain increases as strain-rate increases [1]. Therefore, several material models are proposed and used to describe the high strain rate behavior under blast and impact loading. In the process of modelling, mesh dependency in the used finite element (FE) is the key problem because simulation results under high strain-rate conditions are quite sensitive to applied FE mesh size. This paper suggests a criterion that minimizes mesh-dependency in applied FE mesh size on the basis of fracture energy concept. The typical high strain rate models (HJC [2], CSC [3], K\&C [4]) are examined with penetration simulation to check relative sensitivity to the used FE mesh size. Furthermore, improvement in accuracy of simulation results is investigated by applying a unique failure strain value determined according to the proposed criterion.

\section{Size effect on behavior of concrete}

Since concrete is a brittle material which fails due to creation and propagation of internal microcrack in fracture process zone [5], concrete shows different failure behavior according to pattern of internal microcracking. Size of concrete specimen is the factor which makes difference in pattern of internal microcracking. As can be seen in Figure 1 [6], internal crack pattern changes according to size of specimens. And this difference in crack pattern makes the difference in strength and critical strain shown in Figure 2 [6]. The reason of this difference in crack pattern is that shear force cannot reach to bottom of specimen, as height of specimen get longer.

Therefore, size of the concrete specimen should be considered in estimation of fracture energy. This size effect is also observed in element mesh size of FE analysis. When large finite elements are used, each element has a large effect on the structural stiffness. When a single element cracks, the stiffness of the entire structure is largely reduced to fails easily [7]. By focusing on this size effect on 
failure behavior of concrete in FE mesh and specimen, criterion is proposed based on the fracture energy concept and numerical experiment for the size effect is conducted at the next chapter.

(3)

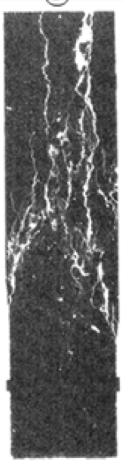

(4)

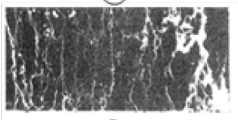

(5)

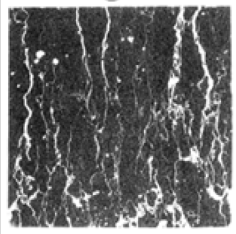

(6)

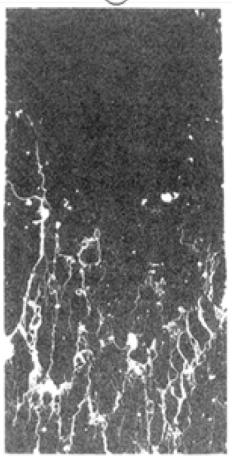

Figure 1: Crack patterns for different size of specimens.

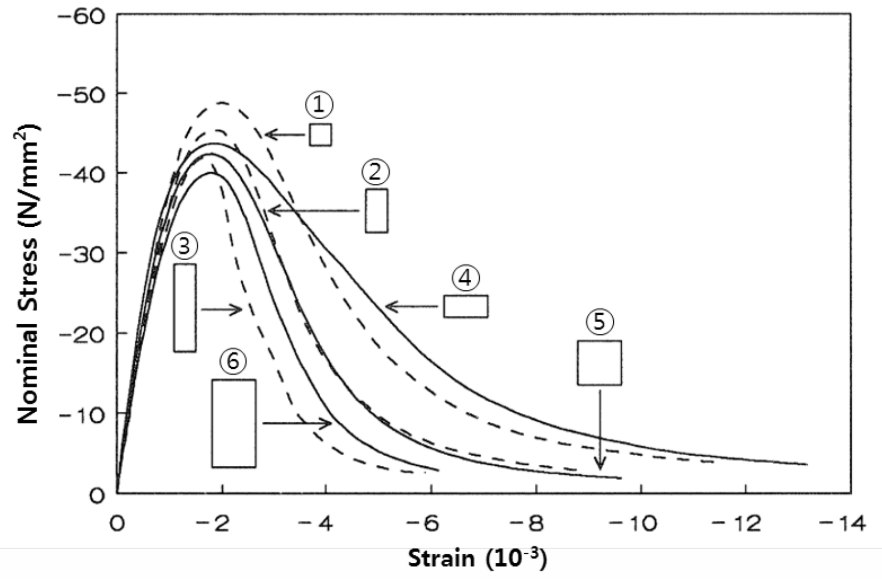

Figure 2: $\quad$ Stress-Strain curve for different size of specimens.

\section{Introduction of a fracture energy based criterion}

\subsection{Estimation of fracture energy}

As can be seen in Figure 3(a) [6], fracture energy is divided into continuum damage energy part and local fracture energy part. Continuum damage energy represents strain hardening portion which varies with size of specimen and local fracture energy represents strain softening portion which has constant value regardless of specimen size [7]. Since the main purpose of this paper is 
modification of failure strain according to FE mesh size, local fracture energy which can convert size effect into difference of failure strain is used to propose a criterion. Local fracture energy part can be approximated by the area of a triangle in Figure 3(b) and be fomulated by adding $F(x)$ the size effect function which has length scale. As a result, eqn (1) is the fomulated equation for local fracture energy where $\varepsilon_{0}$ is the failure strain and $\varepsilon_{c}$ is the critical strain.

(a)

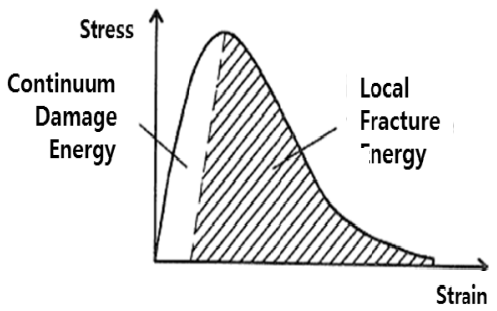

(b)

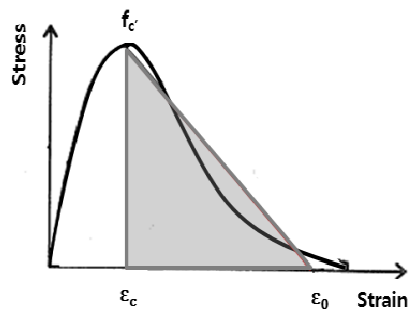

Figure 3: $\quad$ Fracture energy (a) Configuration, (b) Estimation.

$$
G_{f}=\frac{1}{2}\left(\varepsilon_{0}-\varepsilon_{c}\right) f_{c}^{\prime} F(x)
$$

\subsection{Criterion proposal}

The size effect function $F(x)$ consists of $F(b)$ and $F(h) . F(b)$ is the function of specimen width and $F(h)$ is the function of specimen length. First of all, $F(b)$ is estimated. Assuming crack pattern as an exponential function, crack pattern is formulated with $f(x)=\alpha e^{\beta x}$ [7]. When $b$ is width of specimen and center of the specimen is $\mathrm{x}=0$, boundary conditions are $f(0)=1$ and $f(b / 2)=\left(b_{0} / b\right)^{\gamma}$ [9]. Using two boundary conditions, $\alpha=1$ and $\beta=(2 / b)^{\gamma} \ln \left(b_{0} / b\right)$ are gained. $F(b)$ is calculated as eqn (2) by integrating $f(x)$ with $\mathrm{b}$ and inserting maximum length $b_{0}=6(\mathrm{~mm})$ that uniform crack pattern occurs. Fracture energy is given by eqn (3) by subsituting $F(b)$ into eqn (1).

$$
\begin{gathered}
F(b)=\frac{2}{b_{0}} \int_{0}^{b / 2} e^{-\left(\frac{2}{b}\right) \gamma \ln \left(\frac{b}{b_{0}}\right) x} d x=\frac{\left(\left(\frac{b}{6}\right)^{\gamma}-1\right)}{\gamma \ln \left(\frac{b}{6}\right)} \\
G_{f}=\frac{1}{2}\left(\varepsilon_{0}-\varepsilon_{c}\right) f_{c}^{\prime} \frac{\left(\left(\frac{b}{6}\right)^{\gamma}-1\right)}{\gamma \ln \left(\frac{b}{6}\right)} F(h)
\end{gathered}
$$

Regression analysis has been carried out to fomulate $F(h)$ with experiment data of failure strain value according to specimen size. In this procedure, $\gamma=1$ is assumed. As can be seen in Table $1[6,8]$, failure strain is rarely affected by the width of specimen $b$. Subsequently, $F(b)$ is set to the constant value $F(50)$. $F(h)$ is govern by eqn (4), where critical strain $\varepsilon_{c}=0.0135$ that is normal value 
for $48(\mathrm{Mpa})$ concrete and fracture energy $G_{f}=8.5\left(\mathrm{Nmm} / \mathrm{mm}^{2}\right)$ given by experiment [6]. Figure 4 shows result of regression analysis with the data from Table 1.

$$
F(h)=\frac{2 \mathrm{G}_{f}}{\left(\varepsilon_{0}-\varepsilon_{c}\right) f_{c}^{\prime} F(50)}
$$

Table 1: $\quad$ Measured failure strains according to size of specimens.

\begin{tabular}{|c|c|c|}
\hline Height of specimen $(\mathrm{mm})$ & Width of specimen $(\mathrm{mm})$ & Failure strain $\left(\varepsilon_{0}\right)$ \\
\hline 50 & 50 & 0.0103 \\
\hline 50 & 100 & 0.01 \\
\hline 100 & 100 & 0.0069 \\
\hline 100 & 50 & 0.0071 \\
\hline 200 & 50 & 0.0052 \\
\hline 200 & 100 & 0.005 \\
\hline
\end{tabular}

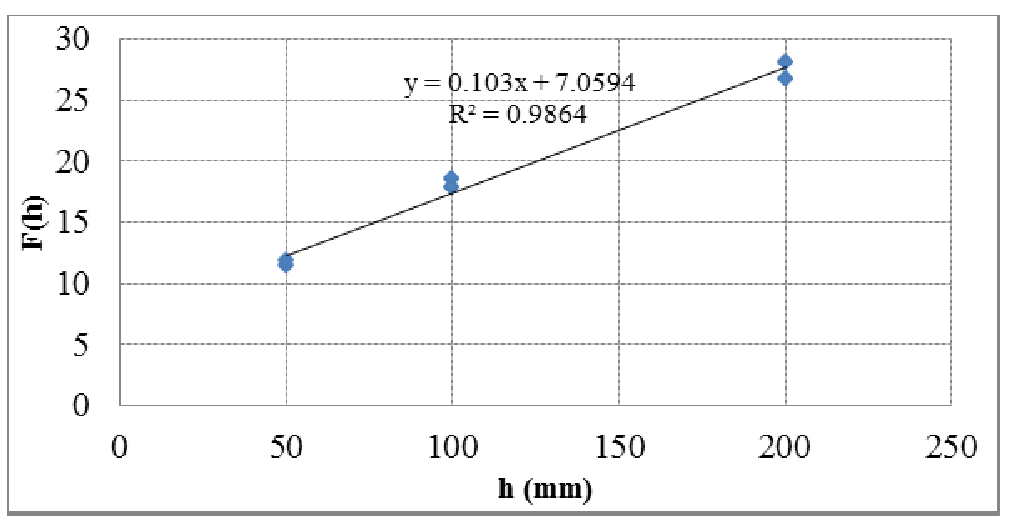

Figure 4: $\quad$ Regression analysis for $F(h)$.

The trend line follows $F(h)$ function. Finally $F(h)$ is governed by eqn (5) and criterion is proposed by eqn (6).

$$
\begin{gathered}
F(h)=0.0103 h+7.06 \\
\varepsilon_{0}=\frac{2 \mathrm{G}_{f} \gamma \ln \left(\frac{b}{b_{0}}\right)}{f_{c}^{\prime}\left(\left(\frac{b}{b_{0}}\right)^{\gamma}-1\right)(0.103 h+7.06)}+\varepsilon_{c}
\end{gathered}
$$

Unique failure strain for each mesh size is proposed by this criterion eqn (6) and applied to FE analysis under high strain rate condition. $b$ is defined as mesh width size and $h$ is defined as mesh height to apply for FE analysis. The optimized value of $\gamma=4.9$, which shows good agreement with being applied to mesh, is assumed. 


\section{Analytical approach}

\subsection{Penetration simulation}

In this section, penetration simulation is performed for $\mathrm{HJC}, \mathrm{CSC}, \mathrm{K} \& \mathrm{C}$ models using LS-DYNA commercial FE analysis program. Projectile radius is 0.0127 $(\mathrm{mm})$ and depth is $144(\mathrm{~mm})$. Plate size is $305(\mathrm{~mm}) \times 305(\mathrm{~mm}) \times 178(\mathrm{~mm})$. Projectile is placed on plate like figure 5 and half modelling is used for saving time. Initial velocity of projectile is $400 \mathrm{~m} / \mathrm{s}$ [10]. Projectile mesh size is fixed to $4.87\left(\mathrm{~mm}^{2}\right)$ and plate mesh size is variable. Residual velocity of projectile after penetration is checked to find out mesh-dependency. Furthermore, after applying failure strain of criterion on concrete plate, residual velocity of projectile is rechecked to confirm improvement in mesh-dependency.

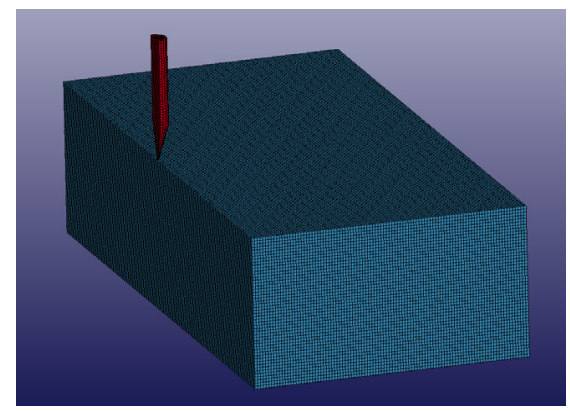

Figure 5: Configuration of penetration simulation.

\subsection{Simulation results}

Each model has 3 sets of cases which has different height of mesh. For case1, plate is divided into 5 pieces along the height direction, for case 2, 10 pieces, and for case 3, 25 pieces. All cases have 6 different width size of mesh. Residual velocity is measured according to mesh width size for each case. Figure 6, 7 and 8 shows the results of simulation for high strain-rate models, where $h$ is height of mesh.

Black lines are case 1, grey lines are case 2, light grey lines are case 3 and dashed lines represent the results of simulation that failure strain of criterion is applied to. Failure strain caculated by criterion is described in Table 2, where h is height of mesh and $b$ is width of mesh. As can be seen in these figures, simulation results before applying criterion shows a significant meshdependency. HJC model has $201(\mathrm{~m} / \mathrm{s})$ difference in simulation results, CSC model has $198(\mathrm{~m} / \mathrm{s})$ and $\mathrm{K} \& \mathrm{C}$ model has $239(\mathrm{~m} / \mathrm{s})$ difference in simulation results according to mesh size. Reliablity of simulation results cannot be assured with these values. When failure strain determined by the criterion is applied to concrete plate in FE anlalysis, variation of simulation results are greatly decreases. As can be seen dashed lines in figure 6, 7, 8, difference in residual velocity is reduced. After criterion is applied to concrete plate, HJC model has 
$121(\mathrm{~m} / \mathrm{s})$ difference in simulation results, CSC model has $131(\mathrm{~m} / \mathrm{s})$ and K\&C model has $100(\mathrm{~m} / \mathrm{s})$ difference in simulation results according to mesh size. In conclusion, mesh dependency in penetration simulation accompanied with high strain rate is improved by using the criterion proposed in this paper.

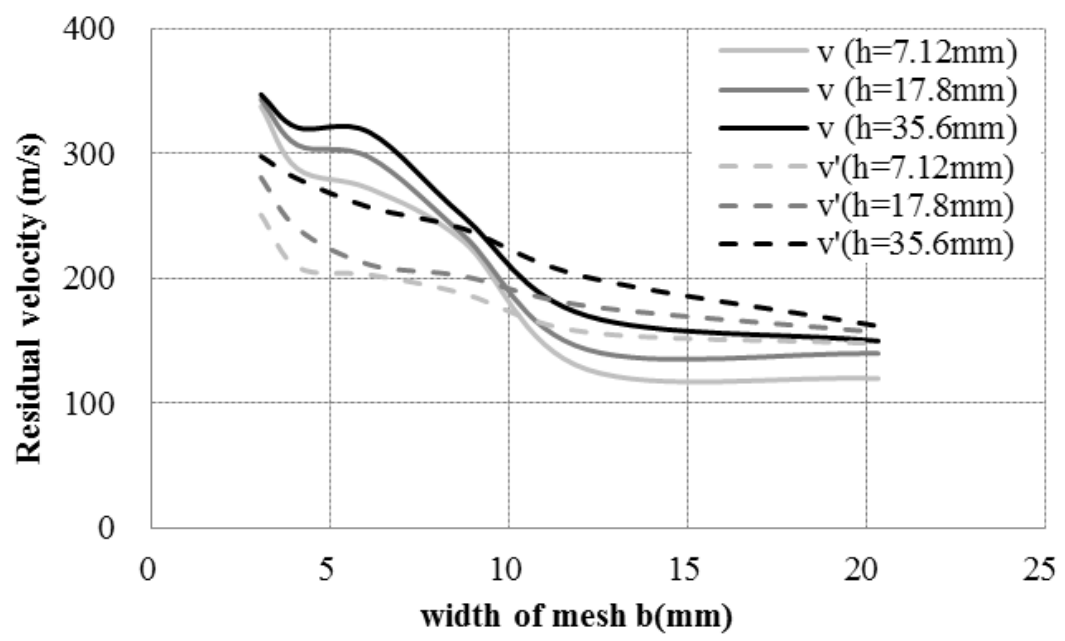

Figure 6: Residual velocity versus width of mesh (HJC model).

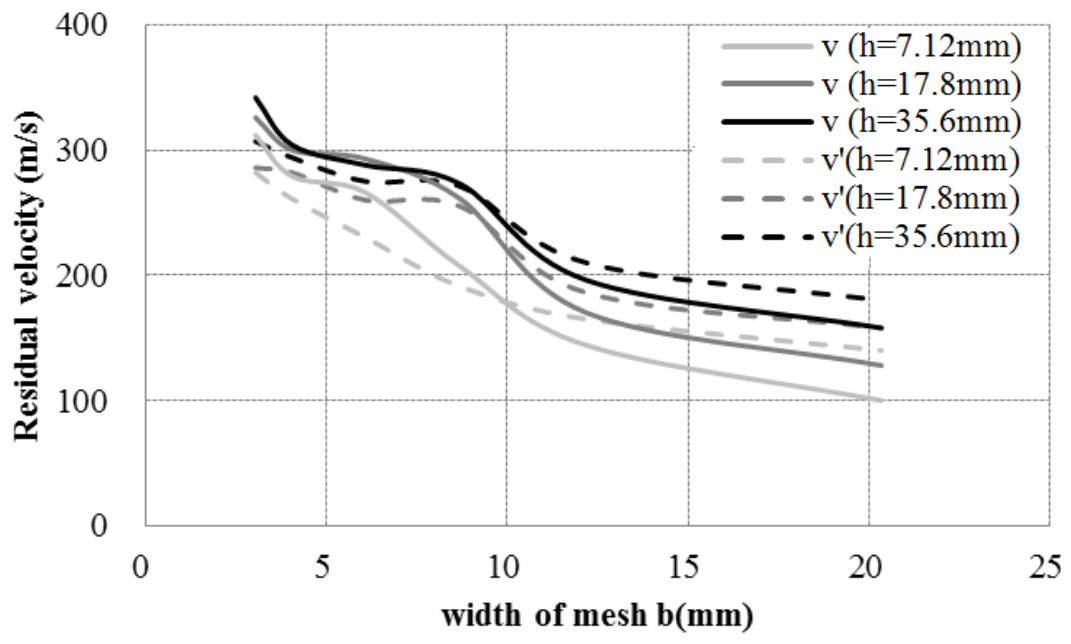

Figure 7: $\quad$ Residual velocity versus width of mesh (CSC model). 
Table 2: $\quad$ Failure strain calculated by criterion according to size of mesh.

\begin{tabular}{|c|c|c|c|}
\hline $\mathrm{b}(\mathrm{mm})$ & Case $1(\mathrm{~h}=35.6 \mathrm{~mm})$ & Case $2(\mathrm{~h}=17.8 \mathrm{~mm})$ & Case $3(\mathrm{~h}=7.12 \mathrm{~mm})$ \\
\hline 3.05 & 0.0354 & 0.0414 & 0.0460 \\
\hline 4.07 & 0.0354 & 0.0414 & 0.0460 \\
\hline 6.1 & 0.034 & 0.0397 & 0.0445 \\
\hline 8.71 & 0.0133 & 0.0154 & 0.0171 \\
\hline 12.2 & 0.00512 & 0.00578 & 0.00634 \\
\hline 20.3 & 0.00187 & 0.00196 & 0.00203 \\
\hline
\end{tabular}

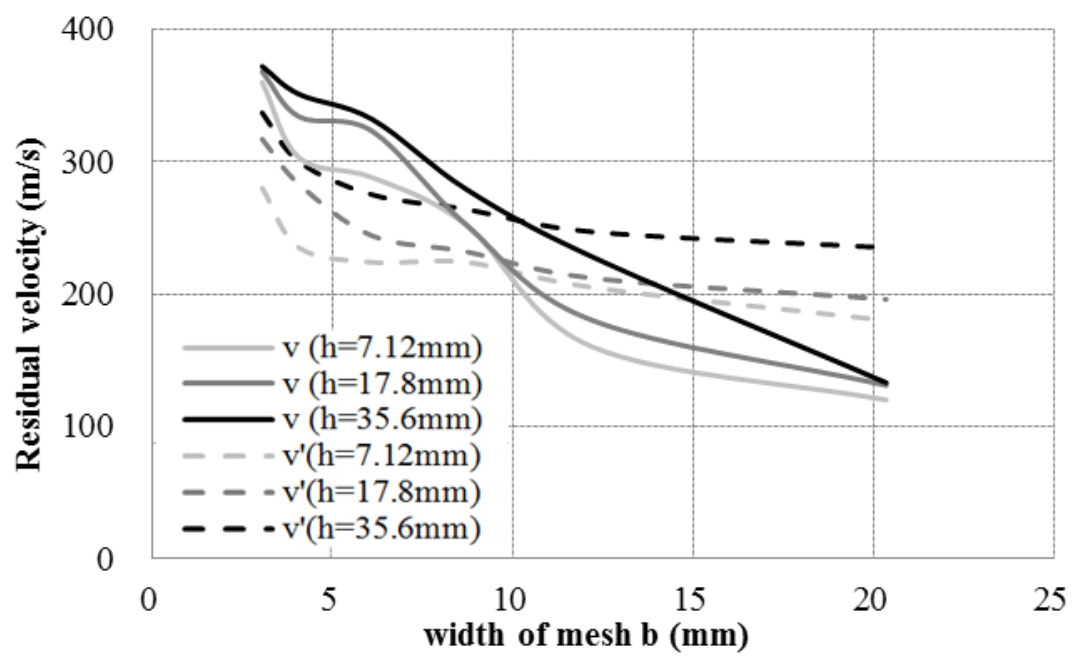

Figure 8: $\quad$ Residual velocity versus width of mesh (K\&C model).

\section{Conclusion}

In this study, the mesh-dependency is investigated in the penetration simulations with high strain-rate models (HJC model, CSC model and $\mathrm{K} \& \mathrm{C}$ model). This study proposes a criterion based on the concept of fracture energy to minimize the mesh-dependency. The analytic approaches for penetration simulation of steel projectile into concrete plate is performed according to the FE mesh size of concrete plate. Simulation results show that the variation of residual velocity with the used FE mesh size is reduced by applying a unique failure strain value determined according to the proposed criterion. In conclusion, the meshdependency in FE analysis of concrete structure subjected to blast and impact loading can be minimized with the criterion proposed in this paper. 


\section{Acknowledgements}

This work is financially supported by Korea Minister of Ministry of Land, Transport and Maritime Affairs (MLTM) as U-City Master and Doctor Course Grant Program, and the Defense Research Laboratory Program of the Defense Acquisition Program Administration and the Agency for Defense Development of Republic of Korea.

\section{References}

[1] Biscoff, P.H. and Perry, S.H., Compressive behavior of concrete at high strain rates. Materials and Structures, 24, pp. 425-450, 1991.

[2] Holmquist, T.J., Johnson, G.R., and Cook, W.H., A computational constitutive model for concrete subjected to large strains, high strain rates, and high pressure. $14^{\text {th }}$ Internal Symposium on Ballistics, Quebec, Canada, pp. 591-600, 1993.

[3] Malvar, L.J., Crawford, J.E., Wesevich, J.W. and Simons, D., A Plasticity Concrete Material Model for DYNA3D. International Journal of Impact Engineering, 19, pp. 847-873, 1997.

[4] Schwer, L.E. and Murray, Y.D., A three-invariant smooth cap model with mixed hardening. International Journal of Numerical and Analytic Methods in Geomechanics, 18, pp. 657-688, 1994.

[5] Taylor, L.M., Er-Ping Chen and Kuszmaul, J.S., Microcrack-Induced Damage Accumulation in Brittle Rock under Dynamic Loading. Computer Methods in Applied Mechanics and Engineering, 55, pp. 301-320, 1986.

[6] Vonk, R.A., A Micromechanical Investigation of Softening of Concrete Loaded in Compression. Heron, 38(3), 1993.

[7] Kwak, H.G and Filippou, F.C, Finite element analysis of reinforced concrete structures under monotonic loads, Department of civil engineering university of California Berkeley, California, 1990.

[8] Van Mier and J.G.M, Multiaxial Strain-Softening of Concrete, Part 1: Fracture. Materials and Structures, 19(111), pp. 179-190, 1986.

[9] Bazant, Z.P. and Oh, B.H., Crack Band Theory for Fracture of Concrete. Materials and Structures, RILEM, Paris, Vol. 16, pp. 155-176, 1983.

[10] Hanchak, S.J., Forrestal, M.J., Young, E.R. and Ehargott, J.Q., Perforation of Concrete Slabs with $48 \mathrm{Mpa}(7 \mathrm{ksi})$ and $140 \mathrm{MPa}(20 \mathrm{ksi})$ Unconfined Compressive Strengths. International Journal of Impact Engineering, 12(1), pp. 1-7, 1992. 